\title{
Qualidade de um latossolo sob plantio convencional e sistema plantio direto no cerrado baiano, Brasil
}

Este trabalho objetivou avaliar parâmetros físicos e hídricos de um Latossolo de textura franco-arenosa, cultivado com milho sob plantio convencional (PC) e sistema plantio direto (SPD) no Cerrado do Oeste da Bahia, Brasil. O estudo foi conduzido em área experimental situada no município de Luís Eduardo Magalhães, Bahia (BA). Os tratamentos foram, T1: Milho (M) sob Plantio Convencional (PC); T2: M sob Sistema Plantio Direto (SPD) em consórcio com Braquiária (B); T3: M sob SPD em consórcio com B em sucessão à Soja (S), Milheto (Mt) e Algodão (A); e T4: M sob SPD em consórcio com Crotalária (C) utilizando como referência uma área de Cerrado Nativo (CN), de fitofisionomia de Campo Sujo. As amostras foram coletadas nas camadas 0,00 a $0,05 \mathrm{~m} ; 0,05$ a $0,10 \mathrm{~m}$ e 0,10 a 0,20 m e foram utilizadas para determinar a porosidade total (Pt); a macroporosidade (Ma); a microporosidade (Mi); a densidade do solo (Ds) e a disponibilidade de água (AD) por meio da curva de retenção de água no solo (CRA); as frações granulométricas e os teores de carbono orgânico total (COT). A diferença dos valores dos atributos medidos nos tratamentos foi, primeiramente, utilizada para verificar o incremento (+) ou a redução (-) do atributo em relação ao $\mathrm{CN}$ (?ref, \%). Em seguida, os tratamentos foram submetidos à anális de variância e as médias comparadas pelo teste de Duncan ao nível de $5 \%$ significância, bem como à análise de correlação de Pearson para avaliação das relações entre os atributos. O SPD promoveu a qualidade do solo, pelo aumento do carbono orgânico total, do grau de floculação, do conteúdo de água disponível e da microporosidade, além de ter reduzido o teor de argila dispersa em água. Contudo, apresentou maior densidade e resistência a penetração, menor macroporosidade e porosidade total, sem prejuízos para o crescimento e o desenvolvimento das plantas. Assim sendo, conclui-se que o SPD é capaz de promover a estruturação, a qualidade e as funções do solo enquanto recurso natural essencial à vida.

Palavras-chave: Sustentabilidade; Conservação de Solo e Água; Disponibilidade de Água; Manejo de Solo; Cerrado.

\section{Quality of a oxisol under conventional tillage and no-tillage system in the savannah of the west of Bahia, Brazil}

\begin{abstract}
The objective of this work was to evaluate the physical and hydrological parameters of a Oxisol with a sandy loam texture, cultivated with maize under conventional tillage (CT) and no-tillage system (NTS) in the Savanna of the western of Bahia, Brazil. The study was conducted in a experimental area, located in the municipality of Luís Eduardo Magalhães, Bahia, Brazil. The treatments were, T1: Corn (C) under Conventional tillage (CT); T2: C under No-tillage System (NTS) in consortium with Brachiaria (B); T3: C under NTS in consortium with B in succession to treatments were, T1: Corn (C) under Conventional tillage (CT); T2: C under No-tillage System (NTS) in consortium with Brachiaria (B); T3: C under NTS in consortium with B in succession to
Soybean (S), Millet (Mt) and Cotton (Ctn); and T4: C under NTS in consortium with Crotalaria (Crt), having as reference one area of Natural Savannah (NS) of Phytophysiognomy of Campo Soybean (S), Millet (Mt) and Cotton (Ctn); and T4: C under NTS in consortium with Crotalaria (Crt), having as reference one area of Natural Savannah (NS) of Phytophysiognomy of Campo
Sujo. Soil samples were collected in the layers 0.00 to $0.05 \mathrm{~m} ; 0.05$ to $0.10 \mathrm{~m}$ and 0.10 to $0.20 \mathrm{~m}$ and were used to determine, total porosity (Tp); macroporosity (Ma); microporosity (Mi); bulk density (Bd) and water availability (WA) through the water retention curve (WRC); the granulometric fractions and the total organic carbon (TOC). The difference of the values of the attributes measured in the treatments was first used to verify the increase (+) or reduction (-) of the attribute in relation to the NC (?ref, \%). Then, the treatments were submitted to analysis of variance and the means were compared by the Duncan test at the $5 \%$ significance level, as well as the Pearson correlation analysis to evaluate the relationships between the attributes. It was verified that the NTS promoted the soil quality by increasing of total organic carbon, the degree of flocculation, the available water content and microporosity, besides having reduced the clay dispersed in water. However, the NTS presented higher bulk density and resistance to penetration, lower macroporosity and total porosity, without damage to the growth and development of plants. Thus, it is concluded that the NTS is capable of promoting structuring, quality and the functions of the soil, as a natural resource essential to life.
\end{abstract}

Keywords: Sustainability; Soil and Water Conservation; Water Availability; Soil Management; Savannah.

Topic: Uso de Recursos Naturais

Reviewed anonymously in the process of blind peer.
Received: $12 / 04 / 2019$

Approved: 27/05/2019
Marla Oliveira Fagundes (iD

Universidade Federal do Oeste da Bahia, Brasil http://lattes.cnpq.br/5899568156784317

http://orcid.org/0000-0002-9251-9162

marlafag.esa@gmail.com

Diony Alves Reis (D)

Universidade Federal do Oeste da Bahia, Brasil http://lattes.cnpq.br/5707542223794836

http://orcid.org/0000-0003-4270-2978

dionyodin@gmail.com

Roberto Baggatini Portella (D)

Universidade Federal do Oeste da Bahia, Brasil

http://lattes.cnpq.br/3464794820553147

http://orcid.org/0000-0003-4236-3128

roberto.portella@ufob.edu.br

\author{
Fabiano José Perina (1D) \\ Embrapa Algodão, Brasil \\ http://lattes.cnpq.br/2414090933616921 \\ http://orcid.org/0000-0003-4049-3383 \\ fabiano.perina@embrapa.br \\ Julio Cesar Bogiani \\ Embrapa Territorial, Brasil \\ http://lattes.cnpq.br/2124564195422694 \\ http://orcid.org/0000-0002-3357-7944 \\ julio.bogiani@embrapa.br
}

Referencing this:

FAGUNDES, M. O.; REIS, D. A.; PORTELLA, R. B.; PERINA, F. J.; BOGIANI, J. C.. Qualidade de um latossolo sob plantio convencional e sistema plantio direto no cerrado baiano, Brasil. Revista Ibero Americana de Ciências Ambientais, v.10, n.3, p.281-297, 2019. DOI: http://doi.org/10.6008/CBPC2179-6858.2019.003.0024 


\section{INTRODUÇÃO}

O milho (Zea mays L.) é um dos mais importantes cereais cultivados e consumidos no mundo, sendo utilizado na alimentação humana e animal, e como matéria-prima para diversos complexos agroindustriais, evidenciando sua importância socioeconômica (CASTRO et al., 2009; ROLIM et al., 2019). Na Bahia, o cultivo do milho se estende por todo o Estado, em grandes, médias e pequenas propriedades. Estima-se que sejam cultivados 360,1 mil hectares, com a produção de 1,3 milhão de toneladas de milho (CONAB, 2019). No oeste da Bahia, especificamente nas safras de 2016/2017 e 2017/2018 foram colhidas 130 e 180 sacas ha $^{-1}$ (AIBA, 2017 ; 2018) respectivamente, demonstrando a relevância da cultura na região.

O oeste baiano, situado no bioma Cerrado, apresenta relevos planos e suave-ondulados em aproximadamente $70 \%$ da sua superfície. Além disso, as boas condições de drenagem em $89 \%$ dos solos desse bioma têm favorecido o uso da agricultura mecanizada e o cultivo de grãos em grandes áreas (SILVA et al., 2003; FERNANDES et al., 2012) possibilitando a consolidação da região como um dos principais polos produtivos do Brasil, evidenciada, sobretudo, a partir da década de 1980 (BRANNSTROM et al., 2008; SANO et al., 2009; SANO et al., 2011).

Os solos do Cerrado revelam-se favoráveis à agricultura devido às suas propriedades físicas (CAVENAGE et al., 1999), sobretudo as relacionadas à textura e estrutura, contudo o intenso uso desses solos tem efeito negativo sobre os atributos físicos e hídricos, resultando em camadas compactadas, redução das taxas de infiltração de água, na aeração e na permeabilidade dos solos (FONTANA et al., 2016). Uma vez que, a estrutura ideal do solo é aquela que possibilita maior área de contato raiz-solo, suficiente espaço poroso para o movimento de água e gases, pouca resistência do solo à penetração das raízes (KOPPI et al., 1991) evidencia-se a necessidade de sistemas de manejo conservacionistas, visando menor impacto ambiental e que promovam a sustentabilidade agrícola neste bioma (DORAN et al., 1994; LAL, 1998; AULER et al., 2014).

Predominantemente os solos têm sido manejados por meio de preparos periódicos com o uso de grades pesadas, arados, escarificadores, subsoladores e grade niveladora, caracterizando o Plantio Convencional (PC) (FONTANA et al., 2016). Por outro lado, sistemas de preparo reduzidos do solo e com revolvimento mínimo têm sido observados. Nesse sentido, em menor proporção e incentivado por instituições de Ensino e Pesquisa, o Sistema Plantio Direto (SPD) tem sido estimulado como alternativa ao PC (FONTANA et al., 2016) adotado na região.

O SPD é conceituado como sistema de manejo conservacionista, que envolve técnicas objetivando a conservação física e química dos solos, fundamentadas na ausência de revolvimento e cobertura permanente do solo por meio da rotação de culturas (HECKLER et al., 2002; LAL, 2004; NUNES et al., 2015). Historicamente o SPD tem sido reconhecido como uma importante prática para a sustentabilidade de sistemas intensivos de produção agrícola, devido aos benefícios, tais como, aumento da infiltração e disponibilidade de água para as plantas; menor taxa perda de solo e nutrientes por erosão, menor tempo de trabalho de máquinas, reduzido consumo de combustível e redução da poluição recursos hídricos, em comparação com PC, (LAL, 2004; SOANE et al., 2012). 
Por outro lado, a compactação de solos manejados sob SPD tem sido frequentemente relatada (REICHERT et al., 2009; NUNES et al., 2014; NUNES et al., 2015) e limitações ao desenvolvimento radicular têm sido discutidas (LIPIEC et al., 2012; NOSALEWICZ et al., 2014) devido à reduzida absorção de água e nutrientes pelas plantas comprometendo o rendimento das culturas (CHEN et al., 2011).

Assim, os efeitos dos sistemas de manejo do solo têm sido avaliados a partir da quantificação de diversos parâmetros físicos, químicos e biológicos. Rós et al. (2012) encontraram menores valores de Macroporosidade e maiores valores de Densidade e Resistencia à Penetração em um solo de textura arenosa sob SPD quando comparado com o PC. Oliveira et al. (2012) observaram aumento dos teores de carbono orgânico nas camadas superficiais em um Neossolo sob sistemas com mobilização reduzida e Oliveira et al. (2019) verificaram Curvas de Retenção de Água no solo com valores maiores de disponibilidade de água em um Latossolo de textura argilosa sob SPD.

Apesar do bioma Cerrado ocupar lugar de destaque em termos agrícolas, informações técnicas e dados científicos sobre como os sistemas de manejo promovem alterações nas funções do solo ainda são escassos, o que gera a necessidade de pesquisas a fim de promover a sustentabilidade neste bioma. De acordo com Auler et al. (2014), as características físicas e hídricas são extremamente afetadas pelos sistemas de manejo, assim sendo, este trabalho teve como objetivo avaliar parâmetros físicos e hídricos de um Latossolo Vermelho Amarelo distrófico de textura franco-arenosa, cultivado com milho sob plantio convencional (PC) e sistema plantio direto (SPD) no Cerrado da região Oeste da Bahia, Brasil.

\section{MATERIAIS E MÉTODOS}

\section{Área de Estudo}

O estudo foi realizado na área experimental da Fundação de Apoio à Pesquisa e Desenvolvimento do Oeste da Bahia (Fundação Bahia), localizada no município Luís Eduardo Magalhães, no extremo Oeste do Estado da Bahia, Brasil, sendo as coordenadas geográficas do experimento: $12^{\circ} 5^{\prime} 36.52^{\prime \prime}$ S de latitude Sul e $45^{\circ} 42^{\prime} 40.30^{\prime \prime} 0$ de longitude Oeste. A área está inserida no bioma Cerrado, que apresenta duas estações climáticas distintas, uma chuvosa, entre os meses de outubro e março, com precipitação média de $1500 \mathrm{~mm}$; e uma estação seca, sem precipitações nos demais meses. A temperatura média anual gira em torno de $22^{\circ}$ a 27으 (MALHEIROS, 2016), sendo o clima classificado como do tipo Aw, conforme a classificação climática de Köppen-Geiger (ALVARES et al., 2013).

O solo da área experimental é classificado como Latossolo Vermelho amarelo distrófico, encontrado em toda porção ocidental do Oeste baiano, sendo definido por Reis et al. (2010) como um solo de médio potencial e de baixa a média aptidão agrícola. O solo da área estudada apresenta textura franca-arenosa ( $804 \mathrm{~g} \mathrm{~kg}^{-1}$ de areia, $74 \mathrm{~g} \mathrm{~kg}^{-1}$ de silte, e $125 \mathrm{~g} \mathrm{~kg}^{-1}$ de argila) até a profundidade de 0,20 m.

O delineamento experimental foi o de casualização por blocos com quatro repetições sendo os tratamentos: T1: Milho (M) sob Plantio Convencional (PC); T2: M sob Sistema Plantio Direto (SPD) em consórcio com Braquiária (B); T3: M sob SPD em consórcio com B em sucessão à Soja (S), Milheto (Mt) e 
Algodão (A); e T4: M sob SPD em consórcio com Crotalária (C), tendo como referência uma área de Cerrado Nativo (CN), não antropizada e de fitofisionomia de Campo Sujo, adjacente ao experimento. O histórico de cultivo da área nos últimos cinco anos é apresentado na Tabela 1.

Tabela 1: Descrição da rotação de culturas de cada tratamento.

\begin{tabular}{|l|l|l|l|l|l|l|l|}
\hline Tratamentos* & Sistema & $2012 / 13$ & $2013 / 14$ & $2014 / 15$ & $2015 / 16$ & $2016 / 17$ & $2017 / 18$ \\
\hline T1 & PC & $\mathrm{M}$ & $\mathrm{M}$ & $\mathrm{M}$ & $\mathrm{M}$ & $\mathrm{M}$ & $\mathrm{M}$ \\
\hline T2 & SPD & $\mathrm{S}$ & $\mathrm{M}+\mathrm{B}$ & $\mathrm{S}$ & $\mathrm{M}+\mathrm{B}$ & $\mathrm{S}$ & $\mathrm{M}+\mathrm{B}$ \\
\hline T3 & SPD & $\mathrm{Mt}+\mathrm{A}$ & $\mathrm{S}+\mathrm{Mt}$ & $\mathrm{M}+\mathrm{B}$ & $\mathrm{A}$ & $\mathrm{S}+\mathrm{Mt}$ & $\mathrm{M}+\mathrm{B}$ \\
\hline T4 & SPD & $\mathrm{Mt}+\mathrm{A}$ & $\mathrm{S}+\mathrm{C}$ & $\mathrm{M}+\mathrm{C}$ & $\mathrm{A}$ & $\mathrm{S}+\mathrm{C}$ & $\mathrm{M}+\mathrm{C}$ \\
\hline
\end{tabular}

*PC: Plantio Convencional; SPD: Sistema Plantio Direto; M: Milho; S: Soja; Mt: Milheto; B: Braquiária; A: Algodão; C: Crotalária. T1: Milho (M) sob Plantio Convencional (PC); T2: Milho (M) sob Sistema Plantio Direto (SPD) em consórcio com Braquiária (B); T3: Milho (M) sob SPD em consórcio com Braquiária (B) em sucessão à Soja (S), Milheto (Mt) e Algodão (A); e T4: Milho (M) sob SPD em consórcio com Crotalária (C).

\section{Amostragem do solo}

As amostras de solo foram coletadas nas camadas 0,00 a $0,05 \mathrm{~m} ; 0,05$ a $0,10 \mathrm{~m}$ e 0,10 a 0,20 m, durante o mês de fevereiro de 2018. A escolha das camadas se deu pela influência direta das raízes das culturas utilizadas nos tratamentos, bem como a ação dos sistemas de manejo. Em cada camada foram coletadas três amostras de solo com estrutura preservada, por meio de anéis volumétricos com dimensões aproximadamente de 0,05 m de altura e 0,05 m de diâmetro, totalizando 144 (4 tratamentos $\times 3$ anéis $\times 3$ camadas $x 4$ repetições) amostras que foram utilizadas para a determinação da Densidade do Solo (Ds), da Porosidade Total (Pt), da Microporosidade (Mi) e da Macroporosidade (Ma) e os pontos mais úmidos da Curva de Retenção de Água no Solo (CRA).

Além das amostras indeformadas, também foram coletadas em cada camada uma amostra de solo com estrutura não preservada, utilizando uma pá de corte, totalizando 48 amostras (4 tratamentos x 1 amostra $\times 3$ camadas $\times 4$ repetições), que foram utilizadas para determinar as frações granulométricas, a argila dispersa em água, o teor de carbono orgânico total (COT) e os pontos mais secos da CRA. Além disso, foi realizado em campo testes de Resistencia do Solo à Penetração (RP).

\section{Análises do solo}

Amostras de solo com estrutura preservada foram saturadas por capilaridade durante 48 horas para a determinação da porosidade total do solo $\left(\mathrm{Pt}, \mathrm{m}^{3} \mathrm{~m}^{-3}\right)$, da macroporosidade $\left(\mathrm{Ma}, \mathrm{m}^{3} \mathrm{~m}^{-3}\right)$, da microporosidade $\left(\mathrm{Mi}, \mathrm{m}^{3} \mathrm{~m}^{-3}\right)$ pelo método da mesa de tensão, utilizando uma sucção de coluna de água de $60 \mathrm{~cm}$, que posteriormente foram secas em estufa a $105^{\circ} \mathrm{C}$, até estabelecimento de massa constante (24h), para determinação da Densidade do solo (Ds, $\mathrm{g} \mathrm{cm}^{-3}$ ) (EMBRAPA, 2017).

As frações granulométricas (teores de areia, silte e argila) foram determinadas pelo Método da Pipeta, utilizando $10 \mathrm{~g}$ de terra fina seca em estufa (TFSE), que foram dispersas quimicamente por meio da utilização de $\mathrm{NaOH}$ a $1 \mathrm{~N}$ e fisicamente em mesa de agitação por 24h. Em seguida, as amostras foram acondicionadas em provetas de $1000 \mathrm{ml}$, extraindo-se uma alíquota de $25 \mathrm{ml}$ após o cálculo do tempo de sedimentação (EMBRAPA, 2017). A argila dispersa em água (ADA) foi determinada pelo Método da Pipeta, 
sem a adição de dispersante, conforme Embrapa (2017). O Grau de Floculação (GF) foi determinado pela equação abaixo:

$$
\mathrm{GF}=\left(\frac{\operatorname{Arg}_{\mathrm{dt}}-\mathrm{Arg}_{\mathrm{da}}}{\operatorname{Arg}_{\mathrm{dt}}}\right) 100 \quad \text { Eq. } 1
$$

Onde: Argdt, é a argila obtida com dispersante (total) e $\operatorname{Arg}_{\mathrm{da}}$, é a argila dispersa em água. $\mathrm{O}$ carbono orgânico total (COT) foi determinado por meio da oxidação úmida com $\mathrm{K}_{2} \mathrm{Cr}_{2} \mathrm{O}_{7}$ a 0,0667 mol L ${ }^{-1}$ em meio sulfúrico, empregando-se o calor como fonte de energia. $\mathrm{O}$ excesso de dicromato após a oxidação foi titulado com solução padrão de $\mathrm{Fe}\left(\mathrm{NH}_{4}\right)_{2}\left(\mathrm{SO}_{4}\right) 2.6 \mathrm{H}_{2} \mathrm{O}$ a $0,1 \mathrm{~mol} \mathrm{~L}^{-1}$ (EMBRAPA, 2017). Para a elaboração da curva de retenção de água no solo (CRA), os pontos nas condições de saturação, 10 e $60 \mathrm{cmH}_{2} \mathrm{O}$ foram determinados em mesa de tensão (KLUTE, 1986; RIBEIRO et al., 2016), enquanto os pontos mais secos da curva foram determinados em amostras com estrutura não preservada (porção de terra fina seca ao ar) utilizando o equipamento Dewpoint Potential Meter (WP4c) (BONINI, 2015; REIS et al., 2016).

Após a leitura do $\Psi_{\mathrm{m}}(\mathrm{MPa})$ no WP4c, as amostras foram pesadas, secas em estufa por um período mínimo de $24 \mathrm{~h}$ à $105 \stackrel{\circ}{\circ} \mathrm{C}$, sendo determinado o conteúdo volumétrico de água $\left(\theta, \mathrm{m}^{3} \mathrm{~m}^{-3}\right)$ (EMBRAPA,2017), ajustando-se os dados experimentais da CRA pelo modelo de van Genuchten (1980) com um uso do programa MATHCAD 2000 e os valores iniciais dos parâmetros sugeridos por Carsel et al. (1988), considerando a textura do solo.

O conteúdo de água na capacidade de campo $\left(\theta_{C C}\right)$ e no ponto de murcha permanente $\left(\theta_{\mathrm{PMP}}\right)$ foi considerado como sendo os valores ajustados de conteúdo de água volumétrico em equilíbrio a $\Psi_{m}=0,0102$ e 1,5 MPa, respectivamente e a água disponível (AD) foi calculada pela diferença do conteúdo de água volumétrico entre o ponto de murcha e a capacidade de campo, conforme adotado por Reynolds et al. (2007) e Reis et al. (2018).

A determinação da Resistência do Solo à Penetração se deu na profundidade de até $60 \mathrm{~cm}$, por meio do Penetrômetro de impacto, modelo Stolf (IAA/PLANALSUCAR/STOLF), pesando $4 \mathrm{~kg}$ com impacto em curso de queda livre de 0,40 m; cone com 0,0128 m de diâmetro, área de $1,29 \mathrm{~cm}^{2}$, ângulo sólido de 30, haste com diâmetro aproximado de 0,01 m (VOGEL et al., 2017) e sendo o peso total do equipamento de 7,2 Kg. A cada impacto foram registrados os valores do deslocamento (metros), os quais foram convertidos em pressão de penetração ou resistência à penetração ( $\mathrm{MPa})$, a partir da divisão do número de impactos pelo deslocamento da profundidade, sendo esse valor multiplicada por 10 (STOLF, 1991). A unidade de impactos $\mathrm{dm}^{-1}$ foi corrigida para MPa.

\section{Procedimento estatístico}

A normalidade dos dados foi verificada pelo teste de Shapiro-Wilk (W) $(n \leq 200)$ (RAZALLI et al., 2011). Valores discrepantes (outliers) foram identificados e excluídos através das medidas do limite inferior (LI) e do limite superior (LS), considerando o primeiro quartil (Q1), o terceiro quartil (Q3) e 1,5 amplitude interquartílica. Os tratamentos foram comparados através da diferença percentual do valor do parâmetro no tratamento, evidenciado seu incremento (+) ou diminuição (-) em relação ao $\mathrm{CN}(\Delta$ ref, \%) e, excluindo-se o 
CN, os tratamentos foram submetidos à análise de variância (Anova), as médias foram comparadas pelo teste de Duncan $(p<0,05)$. Ademais, por meio do coeficiente de correlação de Pearson $(r)$, ao nível de significância $(p<0,05)$, as relações entre as variáveis foram verificadas, utilizando-se o software Statistical Analyses System Institute (SAS, 1999).

\section{RESULTADOS E DISCUSSÃO}

Na Tabela 2 estão dispostos os valores das médias e os desvios-padrão da Macroporosidade (Ma) e Microporosidade $(\mathrm{Mi})$ do solo sob os tratamentos, tendo uma área de Cerrado nativo como referência ( $\Delta$ ref, $\%)$.

Tabela 2: Média e desvio-padrão da Macroporosidade (Ma) e Microporosidade (Mi) de um Latossolo cultivado com Milho sob plantio convencional (PC) e sistema plantio direto (SPD) em comparação com um Cerrado nativo (CN) de fitofisionomia de campo sujo ( $\Delta$ ref, \%) no Oeste da Bahia, Brasil.

\begin{tabular}{|c|c|c|c|c|}
\hline \multirow[t]{3}{*}{ Tratamentos } & $\mathrm{Ma}$ & $\Delta$ ref (\%) & Mi & $\Delta$ ref (\%) \\
\hline & \multicolumn{4}{|c|}{ 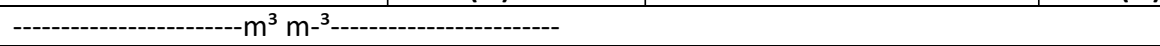 } \\
\hline & \multicolumn{4}{|l|}{$0,00-0,05 \mathrm{~m}$} \\
\hline $\mathrm{T} 1$ & $0,12 \pm 0,05 a$ & $-14,29$ & $0,25 \pm 0,07 a$ & 4,17 \\
\hline $\mathrm{T} 2$ & $0,11 \pm 0,06 a$ & $-21,43$ & $0,25 \pm 0,05 a$ & 4,17 \\
\hline T3 & $0,10 \pm 0,03 a$ & $-28,57$ & $0,26 \pm 0,02 a$ & 8,33 \\
\hline T4 & $0,09 \pm 0,03 a$ & $-35,71$ & $0,26 \pm 0,03 a$ & 8,33 \\
\hline \multirow[t]{2}{*}{$\mathrm{CN}$} & 0,14 & 100,00 & 0,24 & 100,00 \\
\hline & \multicolumn{4}{|l|}{$0,05-0,10 m$} \\
\hline $\mathrm{T} 1$ & $0,11 \pm 0,05 a$ & $-15,38$ & $0,26 \pm 0.06 a$ & 18,18 \\
\hline $\mathrm{T} 2$ & $0,07 \pm 0,03 a b$ & $-46,15$ & $0,23 \pm 0.02 a$ & 4,55 \\
\hline T3 & $0,06 \pm 0,02 b$ & $-53,85$ & $0,25 \pm 0.02 a$ & 13,64 \\
\hline T4 & $0,09 \pm 0,04 a b$ & $-30,77$ & $0,23 \pm 0,02 a$ & 4,55 \\
\hline \multirow[t]{2}{*}{$\mathrm{CN}$} & 0,13 & 100,00 & 0,22 & 100,00 \\
\hline & \multicolumn{4}{|l|}{$0,10-0,20 \mathrm{~m}$} \\
\hline $\mathrm{T} 1$ & $0,10 \pm 0.05 a$ & $-23,08$ & $0,26 \pm 0,05 a b$ & 4,00 \\
\hline $\mathrm{T} 2$ & $0,06 \pm 0.03 b c$ & $-53,85$ & $0,24 \pm 0,02 b$ & $-4,00$ \\
\hline T3 & $0,05 \pm 0.01 \mathrm{c}$ & $-61,54$ & $0,27 \pm 0,03 a$ & 8,00 \\
\hline T4 & $0,08 \pm 0.02 \mathrm{ab}$ & $-38,46$ & $0,24 \pm 0,03 \mathrm{~b}$ & $-4,00$ \\
\hline $\mathrm{CN}$ & 0,13 & 100,00 & 0,25 & 100,00 \\
\hline
\end{tabular}

* Médias seguidas pela mesma letra minúscula nas colunas, dentro de cada parâmetro e camada de solo avaliada não diferem pelo teste de Duncan a 5 \%. T1: Milho (M) sob Plantio Convencional (PC); T2: Milho (M) sob Sistema Plantio Direto (SPD) em consórcio com Braquiária (B); T3: Milho (M) sob SPD em consórcio com Braquiária (B) em sucessão à Soja (S), Milheto (Mt) e Algodão (A); e T4: Milho (M) sob SPD em consórcio com Crotalária (C).

Conforme observado na Tabela 2, na camada de 0,00 a 0,05 m, não houve diferença significativa entre os valores de Ma nos tratamentos sob PC e SDP. Contudo, nas camadas de 0,05 a 0,10 m e de 0,10 a 0,20 m, os valores de Ma observados em T1 foram maiores do que em T3. Isso se dá pelo fato de a Ma ser influenciada pelo sistema de manejo (NEVES JUNIOR et al., 2013). Resultados semelhantes foram encontrados por Silva et al. (2008), ao comparar PC e SPD em um Latossolo Vermelho Distrófico com cultivo de milho e feijão, verificaram na camada de 0,10 a 0,20 m os valor de Ma no solo sob PC de $0,26 \mathrm{~m}^{3} \mathrm{~m}^{-3}$, e no solo sob SPD o valor de $0,17 \mathrm{~m}^{3} \mathrm{~m}^{-3}$. Segundo os autores, esta diferença deve-se ao revolvimento do solo por meio da gradagem e arado, que reorganiza e quebra os agregados, favorecendo a Ma no solo sob PC em contraste ao SPD, que não passa por esse processo.

De maneira geral, observa-se que o $\Delta$ ref (\%) da Ma (Tabela 2) no CN é maior em todas as camadas quando comparado com PC e SPD, evidenciando a sensibilidade da Ma às práticas de manejo. Balbino et al. 
(2003) afirmam que a Ma é um dos atributos mais afetados pelas práticas agrícolas, principalmente nas camadas superficiais. Similarmente, Hickmann et al. (2012), que estudaram um Argissolo sob PC e SPD, comparado com um solo sob vegetação nativa, encontraram valores de Ma maiores no solo sob condições naturais e atribuíram estes resultados ao sistema inalterado que a área de referência representava, preservando a sua estrutura, ou seja, as atividades antrópicas reduzem a qualidade estrutural do solo e consequentemente, as funções atribuídas à Ma, infiltração e aeração.

Diferenças estatísticas não foram observadas na Mi, (Tabela 2) entre os tratamentos nas camadas de 0,00 a 0,05 m e 0,05 a 0,10 m. Porém, na camada de 0,10 a 0,20 m, os tratamentos T2 e T4, que não diferiram entre si, mas diferenciaram-se do T3, o que pode estar associado às interações entre as culturas e rotações, haja vista que os três tratamentos são sob SPD. Resultado semelhante foi observado por Silva et al. (2018) em um Latossolo Vermelho distroférrico típico, comparando PC e SPD, onde, na camada de 0,10 a 0,20 m, o Nabo sob SPD em sucessão à Soja apresentou valor de Mi de $0,41 \mathrm{~m}^{3} \mathrm{~m}^{-3}$, e a Aveia em SPD em sucessão ao Milho apresentou valor de 0,43 $\mathrm{m}^{3} \mathrm{~m}^{-3}$. Segundo Mazurana et al. (2013) e Carmo et al. (2018) a Mi é pouco influenciada pela cobertura vegetal e tráfego sobre o solo, mas às características intrínsecas do solo, como a textura e o teor de matéria orgânica.

Os tratamentos em geral proporcionam um reduzido aumento da $\mathrm{Mi}$, quando comparados com o $\mathrm{CN}$ (Tabela 2). Esse fato corrobora o encontrado no trabalho de Carneiro et al. (2009), o qual avaliou dois tipos de solo do Cerrado sob diferentes sistemas de manejo na camada de 0,00 a 0,10 m, sendo um deles um Latossolo Vermelho, no qual o cultivo de Milheto sob PC, Nabo sob SPD e Sorgo sob SPD apresentaram valores de Mi de $0,36 \mathrm{~m}^{3} \mathrm{~m}^{-3}, 0,34 \mathrm{~m}^{3} \mathrm{~m}^{-3} \mathrm{e} 0,40 \mathrm{~m}^{3} \mathrm{~m}^{-3}$ respectivamente, enquanto o valor de Mi no solo sob mata nativa foi $0,33 \mathrm{~m}^{3} \mathrm{~m}^{-3}$. Na Tabela 3 são apresentados as médias e os desvios-padrão da Porosidade total (Pt) e Densidade (Ds) do solo sob Plantio Convencional e Sistema Plantio Direto, tendo uma área de Cerrado nativo (CN) como referência ( $\Delta$ ref, \%).

Na camada de 0,00 a 0,05 m não foram constatadas diferenças estatísticas nos valores de Pt (Tabela 3) entre os tratamentos. Contudo, nas camadas seguintes os tratamentos sob SPD reduziram os valores Pt em relação ao PC. Nogueira et al. (2016), verificaram menor Pt em um Latossolo Vermelho Distrófico com textura argilosa sob SPD, de três anos, contrastando com o PC. Ademais, Gozubuyuk et al. (2014), ao analisar um Cambissolo de textura arenosa na camada de 0,00 a 0,10 m sob diferentes sistemas de manejo, também observaram que o solo sob SPD apresentou o menor valor $\left(0,48 \mathrm{~m}^{3} \mathrm{~m}^{-3}\right)$ de Pt em relação ao PC $\left(0,50 \mathrm{~m}^{3} \mathrm{~m}^{-}\right.$ ${ }^{3}$ ), atribuindo esses resultados ao preparo do solo. Contudo, Corsini et al. (1999) afirmaram que tal condição, deixará de existir com o passar dos anos, uma vez que às frequentes deposições de resíduo orgânicos oriundos da palhada proporcionam melhoria às características físicas, aumentando os valores de Pt.

Silva et al. (2018) afirmam que a menor mobilização do solo e movimentação de máquinas e implementos agrícolas, como o que ocorre no SPD, reduz a Pt e mudam a distribuição do tamanho dos poros, com redução da $\mathrm{Ma}$, corroborando os resultados observado neste estudo. Assim, observa-se que o volume total de poros foi modificado pelos sistemas de manejo, que consequentemente, promovem alterações na dinâmica de água e gases, no armazenamento de água no solo, na infiltração, bem como na disponibilidade 
de água para as culturas, mas este fato, ao longo do tempo, é convertido pela melhoria da estrutura do solo devido ao aporte de compostos orgânicos (CORSINI et al., 1999).

Tabela 3: Média e Desvio-padrão da Porosidade Total ( $\mathrm{Pt}$ ) e Densidade (Ds) de um Latossolo cultivado com Milho sob plantio convencional (PC) e sistema plantio direto (SPD) em comparação com um Cerrado nativo (CN) de fitofisionomia de campo sujo ( $\Delta$ ref, \%) no Oeste da Bahia, Brasil.

\begin{tabular}{|c|c|c|c|c|}
\hline \multirow[t]{3}{*}{ Tratamentos } & Pt & $\Delta$ ref & Ds & $\Delta$ ref \\
\hline & $\mathrm{m}^{3} \mathrm{~m}^{-3}$ & $(\%)$ & $\mathrm{g} \mathrm{cm}^{-3}$ & (\%) \\
\hline & \multicolumn{4}{|l|}{$0.00-0,05 \mathrm{~m}$} \\
\hline $\mathrm{T} 1$ & $0,37 \pm 0,03 \mathrm{a}$ & $-2,63$ & $1,45 \pm 0,02 b$ & 0,33 \\
\hline $\mathrm{T} 2$ & $0,37 \pm 0,04 a$ & $-2,63$ & $1,49 \pm 0,15 b$ & 3,10 \\
\hline T3 & $0,37 \pm 0,04 a$ & $-2,63$ & $1,45 \pm 0,14 b$ & 0,33 \\
\hline T4 & $0,35 \pm 0,04 \mathrm{a}$ & $-7,89$ & $1,61 \pm 0,06 \mathrm{a}$ & 11,40 \\
\hline \multirow[t]{2}{*}{$\mathrm{CN}$} & 0,38 & 100,00 & 1,45 & 100,00 \\
\hline & \multicolumn{4}{|l|}{$0,05-0,10 m$} \\
\hline T1 & $0,37 \pm 0,03 a$ & 5,71 & $1,53 \pm 0,04 b$ & 6,53 \\
\hline $\mathrm{T} 2$ & $0,30 \pm 0,04 b$ & $-14,29$ & $1,70 \pm 0,09$ a & 18,37 \\
\hline T3 & $0,31 \pm 0,04 b$ & $-11,43$ & $1,72 \pm 0,10 \mathrm{a}$ & 19,76 \\
\hline $\mathrm{T} 4$ & $0,32 \pm 0,04 b$ & $-8,57$ & $1,68 \pm 0,04 a$ & 16,97 \\
\hline \multirow[t]{2}{*}{$\mathrm{CN}$} & 0,35 & 100,00 & 1,44 & 100,00 \\
\hline & \multicolumn{4}{|l|}{$0,10-0,20 \mathrm{~m}$} \\
\hline $\mathrm{T} 1$ & $0,36 \pm 0,03 a$ & $-2,70$ & $1,55 \pm 0,05 b$ & 4,98 \\
\hline $\mathrm{T} 2$ & $0,30 \pm 0,03 b$ & $-18,92$ & $1,73 \pm 0,06 a$ & 17,17 \\
\hline T3 & $0,32 \pm 0,03 b$ & $-13,51$ & $1,70 \pm 0,05 a$ & 15,14 \\
\hline $\mathrm{T} 4$ & $0,32 \pm 0,03 b$ & $-13,51$ & $1,68 \pm 0,05 a$ & 13,79 \\
\hline $\mathrm{CN}$ & 0,37 & 100,00 & 1,48 & 100,00 \\
\hline
\end{tabular}

*Médias seguidas pela mesma letra minúscula nas colunas, dentro de cada parâmetro e camada de solo avaliada não diferem pelo teste de Duncan a 5 \%. T1: Milho (M) sob Plantio Convencional (PC); T2: Milho (M) sob Sistema Plantio Direto (SPD) em consórcio com Braquiária (B); T3: Milho (M) sob SPD em consórcio com Braquiária (B) em sucessão à Soja (S), Milheto (Mt) e Algodão (A); e T4: Milho (M) sob SPD em consórcio com Crotalária (C).

De maneira geral, todos os tratamentos, nas três camadas avaliadas apresentaram aumento da Ds quando comparados com o CN (Tabela 3). Na camada de 0,00 a 0,05 m, a Ds diferiu estatisticamente no T4, que apresentou maior valor em relação aos demais tratamentos. Nas camadas de 0,05 a 0,10 m e 0,10 a 0,20 $m$ os valores de Ds também foram maiores no solo sob SPD, que não diferiram entre si, mas que foram estatisticamente distintos do valor observado no T1. O maior valor de Ds verificado no SPD se deve a não mobilização do solo, que é característica do SPD (SILVA et al., 2008), que promove um empacotamento das partículas minerais (PORTUGAL et al., 2012) reduzindo o volume de vazios e consequentemente, promove os valores de Ds. A Figura1 apresenta os resultados de resistência do solo à penetração (Rp) avaliada entre os tratamentos.

A Rp no T1 (PC) apresentou menor valor quando comparado com os tratamentos sob SDP em todas as camadas. Maiores valores de Rp estão na camada de 0,10 a 0,20 m nos tratamentos sob SPD, que foram estatisticamente distintos dos observados no solo sob PC. O não revolvimento do solo, o aumento da Ds, relacionados ao empacotamento das partículas minerais (PORTUGAL et al., 2012) do solo sob SPD contribuem para o aumento da Rp, justificando os resultados obtidos nesse estudo.

Resultado semelhante foi encontrado por Aikins et al. (2012) ao avaliar um Argissolo de textura arenosa cultivado com Milho, Amendoin e Feijão, no qual o SDP apresentou, em dois anos, os maiores valores de $\mathrm{Rp}$ (6,6 e 5,5 MPa) em relação aos demais tratamentos sob solo revolvido (1,17 e 1,18 MPa). Similarmente, Çelik et al. (2019), que avaliaram um Vertissolo Háplico de textura argilosa cultivado com Soja, Milho e Trigo 
sob SDP, verificaram maiores valores de Rp de 2,18; 2,62 e 2,64 MPa nas camadas 0,00 a 0,10; 0,10 a 0,20 e 0,20 a 0,30 m respectivamente. Os autores justificaram os resultados ao efeito cumulativo da pressão exercida pelo tráfego de máquinas e ausência do revolvimento do solo. Assim como, no estudo de Torres et al. (2011) que avaliaram um Latossolo Vermelho de textura franco-argilo-arenosa e verificaram menores valores de Rp no solo sob PC devido ao revolvimento da camada superficial frequentemente preparada. Na Tabela 4 estão dispostos os valores das médias e os desvios-padrões da Argila Natural Dispersa (ADA), Grau de Floculação (GF), Grau de Dispersão (GD) e Carbono Orgânico Total (COT) do solo submetido aos quatro tratamentos, tendo uma área de Cerrado nativo como referência ( $\Delta$ ref, \%).

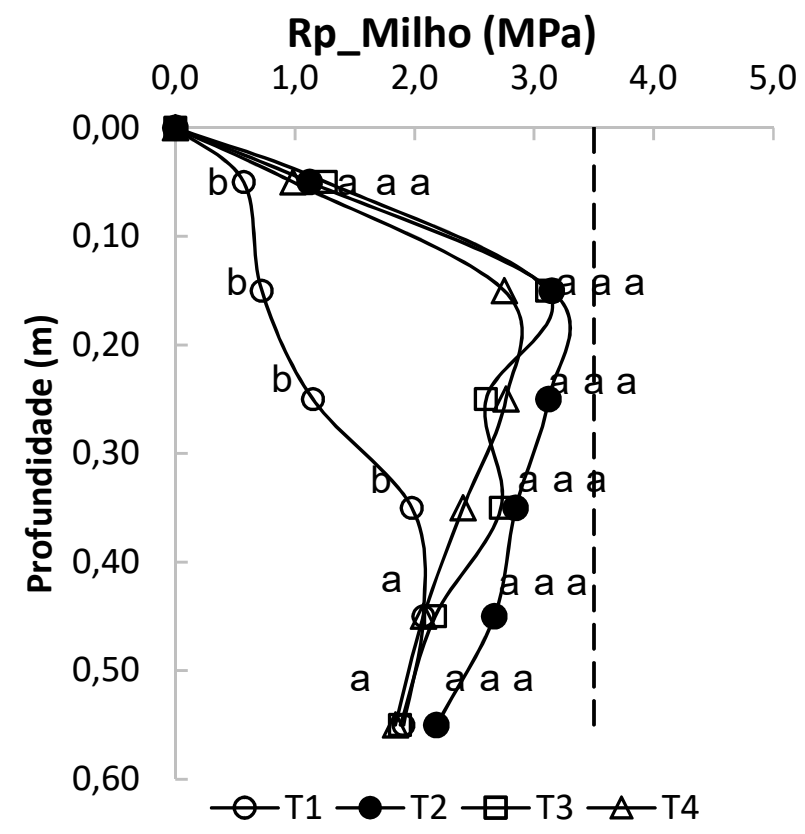

Figura 1: Resistência do solo à Penetração em um Latossolo sob Plantio Convencional (PC) e Sistema Plantio direto (SPD) no Cerrado do Oeste da Bahia. A linha tracejada na vertical indica o valor limitante ao desenvolvimento das plantas sob SPD (MORAES et al., 2014). T1: Milho (M) sob Plantio Convencional (PC); T2: Milho (M) sob Sistema Plantio Direto (SPD) em consórcio com Braquiária (B); T3: Milho (M) sob SPD em consórcio com Braquiária (B) em sucessão à Soja (S), Milheto (Mt) e Algodão (A); e T4: Milho (M) sob SPD em consórcio com Crotalária (C).

As diferenças estatísticas de ADA na camada de 0,00 a 0,05m foram observadas entre T1 e T4. Na camada de 0,05 a 0,10 m T1, T2 e T4 diferiram entre si, e na camada de 0,10 a 0,20 m, apenas T1 e T3 evidenciaram diferenças estatísticas. Porém, de modo geral, o tratamento sob PC apresentou valores maiores de ADA quando comparado com o solo sob SPD e CN (Tabela 4). Diante desse resultado, perceber que PC tem maior tendência para promover as perdas de solo, devido a erosão hídrica e eólica, bem como perda de nutrientes e possível carreamento de contaminantes para cotas mais baixas, diminuindo desse modo a qualidade do solo.

Beutler et al. (2001) encontrou resultados semelhantes ao avaliar o efeito do SPD e PC com cultivo de Milho e Feijão em um Latossolo Vermelho Distrófico de textura argilosa no Cerrado em Minas Gerais. Os autores alegaram esse fato ao maior teor de matéria orgânica devido aos resíduos culturais e ao pouco revolvimento do solo no SPD, resultando em aumento do grau de floculação, o que corrobora com os resultados encontrados neste estudo. 
Tabela 4: Média e Desvio-padrão da Argila Dispersa Natural (ADA), Grau de Floculação (GF), Grau de Dispersão (GD), Carbono Orgânico Total (COT) de um Latossolo cultivado com Milho sob plantio convencional (PC) e sistema plantio direto (SPD) em comparação com um Cerrado nativo (CN) de fitofisionomia de campo sujo ( $\Delta$ ref, \%) no Oeste da Bahia, Brasil.

\begin{tabular}{|c|c|c|c|c|c|c|}
\hline Tratamentos & ADA (\%) & $\Delta$ ref (\%) & GF (\%) & $\Delta$ ref (\%) & COT (g kg-1) & $\Delta$ ref (\%) \\
\hline & \multicolumn{5}{|l|}{$0.00-0,05 \mathrm{~m}$} & \\
\hline T1 & $10.20 \pm 1.79 a$ & 46,55 & $22,97 \pm 6,89 b$ & $-56,94$ & $4,33 \pm 0,51 b$ & $-33,28$ \\
\hline $\mathrm{T} 2$ & $4,87 \pm 0.98 a b$ & $-30,03$ & $54,62 \pm 5,09 a$ & 2,38 & $7,45 \pm 0,80 a$ & 14,79 \\
\hline T3 & $5,60 \pm 0.66 a b$ & $-19,54$ & $39,63 \pm 5,36 a$ & $-25,72$ & $6,65 \pm 0,62$ a & 2,47 \\
\hline T4 & $5,01 \pm 0.57 \mathrm{~b}$ & $-28,02$ & $44,38 \pm 6,85 \mathrm{a}$ & $-16,81$ & $6,53 \pm 0,79 a$ & 0,62 \\
\hline \multirow[t]{2}{*}{$\mathrm{CN}$} & 6,96 & 100 & 53,35 & 100 & 6,49 & 100,00 \\
\hline & \multicolumn{5}{|l|}{$0,05-0,10 m$} & \\
\hline T1 & $9,69 \pm 0.63 \mathrm{a}$ & 40,84 & $25,43 \pm 5,27 b$ & $-34,07$ & $4,33 \pm 0,38 b$ & $-9,98$ \\
\hline $\mathrm{T} 2$ & $6,09 \pm 0,33 c$ & $-11,48$ & $40,80 \pm 3,46 a$ & 5,78 & $6,37 \pm 0,50 a$ & 32,43 \\
\hline T3 & $7,07 \pm 0,75 a b c$ & 2,76 & $41,36 \pm 3,04 a$ & 7,23 & $5,81 \pm 0,48 a$ & 20,79 \\
\hline $\mathrm{T} 4$ & $5,86 \pm 1,05 b$ & $-14,83$ & $41,85 \pm 5,24 a$ & 8,50 & $5,93 \pm 1,95 a$ & 23,28 \\
\hline \multirow[t]{2}{*}{$\mathrm{CN}$} & 6,88 & 100 & 38,57 & 100 & 4,81 & 100,00 \\
\hline & \multicolumn{5}{|l|}{$0,10-0,20 m$} & \\
\hline T1 & $10,54 \pm 0,83 a$ & 61,66 & $21,78 \pm 4,53 b$ & $-45,04$ & $3,91 \pm 1,04 b$ & $-12,13$ \\
\hline $\mathrm{T} 2$ & $7,29 \pm 0,99 a b$ & 11,87 & $46,54 \pm 6,98 a$ & 17,44 & $5,89 \pm 0,80 a$ & 32,36 \\
\hline T3 & $6,78 \pm 0,33 b$ & 3,99 & $34,79 \pm 4,13 a$ & $-12,21$ & $4,89 \pm 0,42 b$ & 9,89 \\
\hline T4 & $7,27 \pm 0,85 a b$ & 11,56 & $38,95 \pm 5,61 a$ & $-1,72$ & $5,77 \pm 1,12 a$ & 29,66 \\
\hline $\mathrm{CN}$ & 6,52 & 100 & 39,63 & 100 & 4,45 & 100,00 \\
\hline
\end{tabular}

*Médias seguidas pela mesma letra minúscula nas colunas, dentro de cada parâmetro e camada de solo avaliada não diferem pelo teste de Duncan a 5 \%. T1: Milho (M) sob Plantio Convencional (PC); T2: Milho (M) sob Sistema Plantio Direto (SPD) em consórcio com Braquiária (B); T3: Milho (M) sob SPD em consórcio com Braquiária (B) em sucessão à Soja (S), Milheto (Mt) e Algodão (A); e T4: Milho (M) sob SPD em consórcio com Crotalária (C).

Com relação a CN, apenas T1 proporcionou aumento de ADA na camada de 0,00 a 0,05 m. Na camada de 0,05 a 0,10 m, T2 e T4 apresentaram reduções no valor de ADA de 11 e 14\%, respectivamente, em relação a $\mathrm{CN}$, enquanto na camada de 0,10 a 0,20 m todos os tratamentos promoveram aumento de ADA, sendo que o solo sob PC (T1) proporcionou aumentou da dispersão do solo em 61\%. A promoção da dispersão da argila pode favorecer a sua eluviação no perfil do solo e produzir horizontes ricos em argila (iluviação), resultando no entupimento de poros, reduzindo a aeração, a infiltração de água (MEURER et al. 2004), bem como pode aumentar os valores de Ds e Rp subsuperficialmente, como observado neste estudo, mas também pode promover os processos erosivos, resultando em perdas de solo, água e nutrientes.

Em se tratando de Grau de Floculação (GF) (Tabela 4), nas camadas avaliadas, menores valores estatisticamente distintos foram observados no solo sob PC (T1) quando comparados com o solo sob SPD, evidenciando que o PC reduz a floculação do solo na camada arável $(0,00$ a $0,20 \mathrm{~m})$ quando comparado com o solo sob SPD. Além disso, evidencia redução da qualidade estrutural, haja vista que a agregação e a estruturação do solo dependem de um sistema floculante.

O tratamento T1 reduziu o GF e T2 o aumentou em todas as camadas avaliadas, quando comparado com o CN (Tabela 4). Pode-se observar que o resultado obtido em T1 é reflexo da ausência da matéria orgânica, já que, segundo Prado et al. (2001) ao observarem o cultivo de cana-de-açúcar sob PC constatouse que a diminuição da matéria orgânica promove a redução do grau de floculação das argilas.

Diante dos resultados obtidos, evidencia-se que o SPD promove a estruturação do solo. lori (2010), afirma que solos com maior agregação, indicado pelo GF, evidenciam maior capacidade de manutenção da estrutura e maior resistência aos processos erosivos. E esse fato se deve, de acordo com Campos et al. (1995), à palhada formada pelos resíduos das culturas anteriores, que após sua decomposição, liberam compostos 
orgânicos que atuam como agentes cimentantes dos agregados do solo, melhorando e promovendo a sua estrutura. Além disso, essa deposição continua de resíduos vegetais, segundo Asmann et al. (2014) promovem o aumento do teor de Carbono no solo.

Valores de COT (Tabela 4) em todas as camadas avaliadas foram maiores no solo sob SPD e estatisticamente diferentes dos valores observados em T1. Nesse sentido, observa-se que os maiores valores de COT em SPD são reflexo da ausência de revolvimento do solo, manutenção e aporte contínuo de resíduos vegetais na superfície do solo. Esse resultado também foi encontrado por Sales et al. (2016), que avaliaram um Latossolo Vermelho Amarelo de textura franco-argilo-arenosa sob PC e SPD que similarmente ao presente estudo, alegaram que o não revolvimento do solo, o tempo de implantação do SPD, a cobertura vegetal produzida pelas sucessões e o possível aumento na densidade radicular, favoreceram maior alocação de Carbono nas camadas do solo.

No $\mathrm{PC}$, menores valores de COT podem estar relacionados à prática de revolvimento do solo por meio da aragem e gradagem, que favorecem a exposição da matéria orgânica, antes protegida fisicamente no interior dos agregados (LOSS et al., 2015) bem como a sua rápida oxidação, reduzindo o COT. Similarmente, Rosa et al. (2011) avaliaram os teores de COT em Planossolo Háplico eutrófico solódico de textura argilosa sob PC e SPD, no Sul do Brasil e observaram que o PC apresentou valores menores de COT em relação ao SPD, principalmente nas camadas superficiais do solo (0,00 a 0,05 e 0,05 a 0,10 m), e justificaram a manutenção da cobertura vegetal e o não revolvimento do solo como responsáveis pelo maior incremento de COT. Além disso, Reis et al. (2016) ao avaliar um Planossolo Háplico eutrófico típico de textura franca com diferentes tempos de implantação de SPD observaram acréscimo de COT nos tratamentos mais antigos. Os autores afirmam que o fato de não haver perturbação do solo por meio do seu revolvimento e consequentemente menor taxa de oxidação da matéria orgânica, os valores de COT no solo são promovidos.

De maneira geral, apenas o 11 reduziu o COT em relação ao $\mathrm{CN}$, e os demais tratamentos $(\mathrm{T} 2, \mathrm{~T} 3, \mathrm{~T} 4)$ em SPD promoveram aumento dos valores desse atributo em todas as camadas. Mas se observa que o COT na área de referência é relativamente baixo e este fato pode estar relacionado aos sucessivos incêndios que o Cerrado, sobretudo o de Fitofisionomia de Campo Sujo, é submetido anualmente nas épocas de seca, contrastando com as áreas experimentais. As queimadas resultam na redução da matéria orgânica e consequentemente efeito semelhante no COT, o que pode ser observado no estudo de Paredes Junior et al. (2015) ao analisar um solo sob cultivo de cana-de-açúcar, com e sem queima da palhada, apresentando melhores resultados em relação ao carbono no segundo caso.

Além disso, o Cerrado campo sujo naturalmente possui baixa produção de biomassa, devido ao predomínio, segundo Ribeiro et al. (2008), de vegetação arbustivo-herbácea, com arbustos e subarbustos esparsos, sendo mais frequentes as famílias Poaceae (Gramínea) e Cyperaceae (aspecto graminóide), evidenciando desse modo, a reduzida capacidade de cobertura do solo, que certamente resultam em menores valores de COT. Carvalho et al. (2017) que compararam quatro fitofisionomias do Cerrado, Campo Sujo Seco (CSS), Cerradão (CE) , Cerrado Típico (Ct) e Mata Seca Sempre Verde (MSSV) verificaram menores valores de COT em CSS e Ct, e atestaram os resultados à textura dos solos, especificamente ao baixo conteúdo 
de argila, que confere ao solo reduzida capacidade de retenção de carbono, corroborando os resultados obtidos na área de referência. As Curvas de Retenção de Água (CRA) no solo são apresentadas na Figura 2 em suas respectivas camadas.

(a)

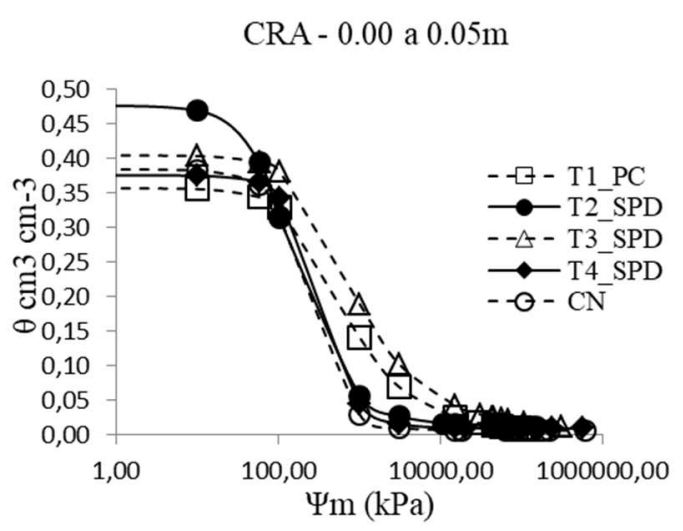

(b)

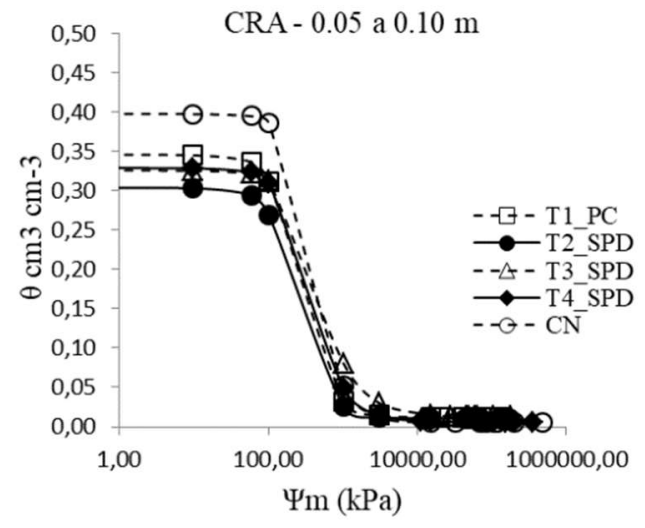

(c)

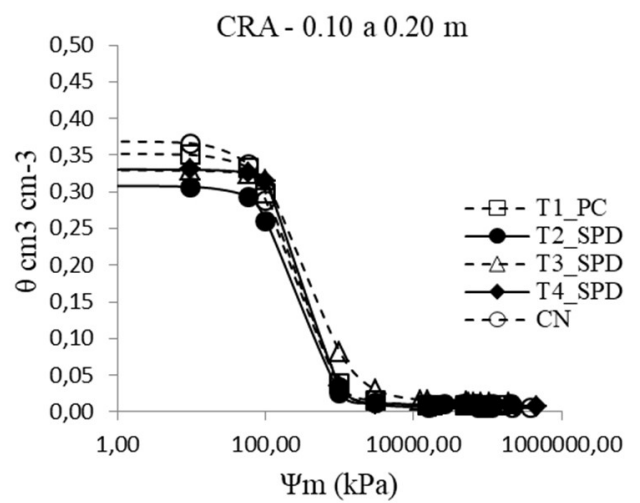

Figura 2: Curvas de Retenção de Água (CRA) de um Latossolo cultivado com Milho sob plantio convencional (PC) e sistema plantio direto (SPD) em comparação com um Cerrado nativo (CN) de fitofisionomia de campo sujo no Oeste da Bahia, Brasil, nas camadas de a) 0,00 a 0,05 m, b) 0,05 a 0,10 m e c) 0,10 a 0,20 m, em diferentes tratamentos.

T1: Milho (M) sob Plantio Convencional (PC); T2: Milho sob Sistema Plantio Direto (SPD) em consórcio com Braquiária

(B); T3: Milho sob SPD em consórcio com B em sucessão à S, Milheto (Mt) e Algodão (A); T4: Milho sob SPD em consórcio com Crotalária (C); e CN: Cerrado Nativo.

No que se refere à retenção de água, verifica-se que os tratamentos sob SPD apresentaram os maiores valores de conteúdo de água, inclusive quando comparados com $\mathrm{CN}$ na camada de 0,0 a 0,05m (Figura 2.a). Logo, demonstra-se que os sistemas de manejo modificam a dinâmica e a capacidade do solo em armazenar água.

No solo sob SPD (T2, T3 e T4) valores de Água Disponível (AD) na camada de 0,00 a 0,05 m foram de $0,30,0,34$ e $0,33 \mathrm{~cm}^{3} \mathrm{~cm}^{-3}$ respectivamente, enquanto o conteúdo de $A D$ em $C N$ foi de $0,31 \mathrm{~cm}^{3} \mathrm{~cm}^{-3}$, enquanto o T1 apresentou $0,30 \mathrm{~cm}^{3} \mathrm{~cm}^{-3}$. O que pode ser explicado pelo maior aporte de matéria orgânica nessa camada devido aos restos vegetais da rotação de culturas, como também pela promoção da Mi que o SPD ocasiona. Resultado semelhante, foi encontrado por Ribeiro et al. (2016) em um Planossolo Háplico eutrófico típico de textura franco-arenosa sob PC e SPD na camada de 0,0 a 0,10m, atribuindo esse resultado à maior quantidade de microporos presentes nessa camada. 
Na Figura 2.b percebe-se uma mudança na curva de retenção, onde o T1 proporcionou maior valor de conteúdo de água em relação aos tratamentos T2, T3 e T4. Contudo, ao comparar com CN, todos os tratamentos apresentam redução. Esse fato pode ser observado também nos valores da água disponível (AD), que foram os seguintes para $T 1, T 2, T 3$ e $T 4: 0,30 \mathrm{~cm}^{3} \mathrm{~cm}^{-3}, 0,26 \mathrm{~cm}^{3} \mathrm{~cm}^{-3}, 0,30 \mathrm{~cm}^{3} \mathrm{~cm}^{-3} \mathrm{e} 0,26 \mathrm{~cm}^{3} \mathrm{~cm}^{-}$ ${ }^{3}$ respectivamente, e $\mathrm{CN}$ apresentou $0,38 \mathrm{~cm}^{3} \mathrm{~cm}^{-3}$. E na última camada avaliada $(0,10$ a $0,20 \mathrm{~m})$ (Figura 2.c) comportamento semelhante foi observado na curva e nos valores de $A D$, que consistiram em $0,28 \mathrm{~cm}^{3} \mathrm{~cm}^{-3}$ para $\mathrm{CN}$, e $0,29 \mathrm{~cm}^{3} \mathrm{~cm}^{-3}, 0,25 \mathrm{~cm}^{3} \mathrm{~cm}^{-3}, 0,30 \mathrm{~cm}^{3} \mathrm{~cm}^{-3}$ e $0,31 \mathrm{~cm}^{3} \mathrm{~cm}^{-3}$ para T1, T2, T3 e T4 respectivamente.

O comportamento da curva nas duas últimas camadas pode ser o reflexo dos maiores valores de Ds (tabela 2) e Rp (figura 1) nos tratamentos T2, T3 e T4 sob SPD, que desse modo, possuem camadas mais adensadas. Além disso, o maior valor de Mi (tabela 1) promovido por T1 sob PC, proporciona maior retenção de água em relação ao SPD. Resultados semelhantes foram encontrados por Dalmago et al.(2009), ao comparar PC e SPD em um Argissolo Vermelho Distrófico típico arenosa com cultivo de milho e ervilhaca, e encontraram valores de $A D$ a partir da profundidade de 0,15 m maiores em PC do que SPD, alegando esse resultado ao efeito da aração, onde a matéria orgânica foi incorporada ao solo em profundidades em torno de $0,15 \mathrm{~m}$. Explicação essa que corrobora com o presente estudo. Na Tabela 6 são apresentados os coeficientes de correlação de Pearson entre os parâmetros avaliados.

Tabela 6: Matriz de Correlação de Pearson dos atributos avaliados de um Latossolo cultivado com Milho sob plantio convencional (PC) e sistema plantio direto (SPD) em comparação com um Cerrado nativo (CN) de fitofisionomia de campo sujo no Oeste da Bahia, Brasil.

\begin{tabular}{|c|c|c|c|c|c|c|c|c|}
\hline$*$ & GF & COT & Ds & $\mathrm{Ma}$ & $\mathrm{Mi}$ & $\mathrm{Pt}$ & $A D$ & $R p$ \\
\hline ADA & $-0.71 * *$ & $-0.45 * *$ & $-0.19 * *$ & $-0.04 n s$ & $0.33^{*}$ & $0.20 *$ & $0.20 \mathrm{~ns}$ & $0.50 \mathrm{~ns}$ \\
\hline GF & & $0.38 * *$ & $0.22 *$ & $-0.13 n s$ & $-0.13 n s$ & $-0.22^{*}$ & $0.52^{*}$ & $-0.40^{*}$ \\
\hline COT & & & $-0.02 n s$ & $0.10 \mathrm{~ns}$ & $-0.21^{*}$ & -0.009 & $0.62 * *$ & $-0.59 * *$ \\
\hline Ds & & & & $-0.63 * *$ & $-0.26 * *$ & $-0.95 * *$ & $0.22 \mathrm{~ns}$ & $0.52^{* *}$ \\
\hline $\mathrm{Ma}$ & & & & & $-0.43 * *$ & $0.63 * *$ & $-0.35^{*}$ & $-0.67 * *$ \\
\hline $\mathrm{Mi}$ & & & & & & $-0.43 * *$ & $0.65 * *$ & $0.46 *$ \\
\hline $\mathrm{Pt}$ & & & & & & & $-0.50 *$ & $0.67 * *$ \\
\hline$A D$ & & & & & & & & $-0.45^{*}$ \\
\hline
\end{tabular}

$\mathrm{n}=48 ;{ }^{*}$ ADA: Argila dispersa em água (\%); GF: Grau de floculação (\%); COT: carbono orgânico total (gkg $\left.{ }^{-1}\right)$; Ds: Densidade do Solo $\left(\mathrm{g} . \mathrm{cm}^{3}\right)$; Ma: Macroporosidade $\left(\mathrm{m}^{3} \mathrm{~m}-{ }^{3}\right)$; Mi: Microporosidade $\left(\mathrm{m}^{3} \mathrm{~m}-{ }^{3}\right)$; Pt: Porosidade Total (\%); AD: Água Disponível $\left(\mathrm{cm}^{3} \mathrm{~cm}^{-3}\right)$; Rp: Resistência a Penetração (Mpa). ns: Não significativa; *: Significativa ao nível de 5\%; **: Significativa ao nível de $1 \%$.

As relações (Tabela 6) evidenciam que o aumento o conteúdo de ADA diminui o GF (-0,71), o COT ($0,45)$ e a Ds $(-0,19)$. Assim, demonstra-se que o PC promove os valores de ADA (Tabela 4), afetando negativamente a floculação do solo e os teores de $C$, que consequentemente afetam a agregação, a estruturação do solo e a disponibilidade de água. Ademais, a Ma, Mi e Pt estiveram correlacionados negativamente com a Ds, que por sua vez relaciona-se positivamente com a Rp.

\section{CONCLUSÕES}

Os resultados observados neste estudo permitem concluir que: O SPD promoveu os valores de COT, GF e AD, evidenciando melhorias na estruturação e agregação do solo, em contraste com o PC; O cultivo de milho sob Plantio Convencional reduz a qualidade do solo, favorecendo as perdas de solo, matéria orgânica 
e água; e o cultivo de milho num Latossolo de textura arenosa cultivado sob Sistema Plantio Direto (SPD) reduziu a $\mathrm{Ma}$, a Pt e aumentou os valores de $\mathrm{Ds}$ e Rp; Os efeitos negativos relacionados ao SPD nos solos do Cerrado evidenciam a necessidade de estudos que avaliem o sistema ao longo do tempo; $\mathrm{O} \mathrm{CN}$, na fitofisionomia Campo Sujo, apresentou baixos valores de COT naturalmente, evidenciando a necessidade de estudos em outras áreas para caracterizar melhor essa fitofisionomia e propor sistemas de manejo que promovam o COT na mesma.

AGRADECIMENTOS: aos apoiadores e financiadores deste trabalho, sobretudo à Fundação de Amparo à Pesquisa do Estado da Bahia (FAPESB); à Coordenação de Aperfeiçoamento de Pessoal de Nível Superior (CAPES); à Fundação de Apoio à Pesquisa e Desenvolvimento do Oeste Baiano (Fundação BA); à Empresa Brasileira de Pesquisa Agropecuária (Embrapa) e à Empresa JCO Indústria e Comércio de Fertilizantes.

\section{REFERÊNCIAS}

AIBA. Associação de Agricultores e Irrigantes do Oeste da Bahia. Anuário da Região Oeste da Bahia: Safra 2016/2017. Culturas. AIBA, 2017

AIBA. Associação de Agricultores e Irrigantes do Oeste da Bahia. Anuário da Região Oeste da Bahia: Safra 2017/2018. Culturas. AIBA, 2018

AIKINS, S. H. M.; AFUAKWA, J. J.. Effect of four different tillage practices on soil physical properties under cowpea. Agriculture and Biology Journal of North America, v.3, p.1724, 2012. DOI: http://10.5251/abjna.2012.3.1.17.24

ALVARES, C. A.; STAPE, J. L.; SENTELHAS, P. C.; GONÇALVES, J. L. M.; SPAROVEK, G.. Köppen's climate classification map for Brazil. Meteorologische Zeitschrift, v.22, p.711-728, 2013. DOI: http://dx.doi.org/10.1127/0941.2948.20130507

ASMANN, J. M.; ANGHINONI, I.; MARTINS, A. P.; COSTA, S. E. V. G. A.; CEGAGNO, D.; CARLOS, F. S.; CARVALHO, P. C. F.. Soil carbon and nitrogen stocks and fractions in a long-term integrated crop-livestock system under no-tillage in southern Brazil. Agriculture, Ecosystems and Environment, v.190, p.52-59, 2014. DOI:

https://doi.org/10.1016/i.agee.2013.12.003

BALBINO, L. C.; BROSSARD, M.; STONE, L. F.; BRUAND, A. LEPRUN, J. C.. Estrutura e propriedades hidráulicas em Latossolos sob cultivo na região do cerrado. Santo Antônio: Embrapa Arroz e Feijão, 2003.

BERTSCH, P. M.; SEAMAN, J. C.. Characterization of complex mineral assemblages: Implications for contaminant transport and environmental remediation. National Acad Sciences, v.96, p.3350-3357, 1990. DOI:

https://doi.org/10.1073/pnas.96.7.3350

BEUTLER, A. N.; SILVA, M. L. N.; CURI, N.; FERREIRA, M. M.; PEREIRA FILHO, I. A.; CRUZ, J. C.. Agregação de Latossolo Vermelho Distrófico Típico relacionada com o manejo na Região dos Cerrados no Estado de Minas Gerais. Revista Brasileira de Ciência do Solo, v.25, p.129-136, 2001. DOI: http://dx.doi.org/10.1590/S0100-06832001000100014
BRANNSTROM, C.; JEPSON, W.; FILIPPI, A. M.; REDO, D.; XU, Z.; GANESH, S.. Land change in the Brazilian savana (Cerrado), 1986-2002: comparative analysis and implications for land-use policy. Land Use Policy, v.25 p.579-595, 2008. DOI: https://doi.org/10.1016/j.landusepol.2007.11.008

CAMPOS, B. C.; REINERT, D. J.; NICOLODI, R.; RUEDELL, J.; PETRERE, C.. Estabilidade estrutural de um Latossolo Vermelho Escuro distrófico após sete anos de rotação de culturas e sistemas de manejo de solo. Revista Brasileira de Ciências do Solo, v.19, p.121-126, 1995.

CARMO, M. C.; CUNICO, J. M.; SANTOS, M. R. G.; SILVA, P. K. M.; SIQUEIRA, M. G.. Densidade e porosidade do solo em pastagem recuperada e degradada, na Amazônia ocidental. Agrarian Academy, v.5 p.154-159, 2018. DOI: $0.18677 /$ Agrarian Academy 2018a15

CARNEIRO, M. A. C.; SOUZA, E. D.; REIS, E. F.; PEREIRA, H. S.; AZEVEDO, W. R.. Atributos físicos, químicos e biológicos de solo de cerrado sob diferentes sistemas de uso e manejo. Revista Brasileira de Ciências do Solo, v.33, n.1, p.147-157, 2009. DOI: http://dx.doi.org/10.1590/S010006832009000100016

CARSEL, R. F.; PARRISH, R. S.. Developing Joint Probability Distributions of Soil Water Retention Characteristics. Water Resources Research, v.24, n.5, p.755-769, 1988.

CARVALHO, D. C.; PEREIRA, M. G.; GUARESCHI, R. F.; MARANHÃO, D. D. C.. Estoque de Carbono e Nitrogênio e Abundância Natural de $\delta 13 C$ na Estação Ecológica de Pirapitinga, MG. Floresta Ambiente, v.24, p.e20150092, 2017. DOI: http://dx.doi.org/10.1590/2179-8087.009215

CASTRO, M. V. L.; NAVES, M. M. V.; OLIVEIRA, J. P.; FROES, L. O.. Rendimento industrial e composição química de milho de alta qualidade proteica em relação a híbridos comerciais. Pesquisa Agropecuária Tropical, Goiânia, v.39, p.233-242, 2009.

CAVENAGE, A.; MORAES, M. L. T.; ALVES, M. C.; CARVALHO, M. A. C.; FREITAS, M. L. M.; BUZETTI, S.. Alterações nas propriedades físicas de um latossolo vermelho-escuro sob 
diferentes culturas. Revista Brasileira de Ciência do Solo, v.23, n.4, p.997-1003, 1999. DOI: http://dx.doi.org/10.1590/S0100-06831999000400027

ÇELIK, I.; GÜNAL, H.; ACAR, M.; ACIR, N.; BARUT, Z. B.; BUDAK, M.. Strategic tillage may sustain the benefits of longterm no-till in a Vertisol under Mediterranean climate. Soil and Tillage Research, v.185, p.17-28, 2019. DOI: https://doi.org/10.1016/j.still.2018.08.015

CHEN, G.; WEIL, R. R.. Root growth and yield of maize as affected by soil compaction and cover crops. Soil and Tillage Research, v.117, p.17-27, 2011. DOI: https://doi.org/10.1016/j.still.2011.08.001

CONAB. Companhia Nacional de Abastecimento. Acompanhamento da Safra Brasileira: Grãos: Safra 2018/19: sexto levantamento. Rio de Janeiro: CONAB, 2019.

CORSINI, P. C.; FERRAUDO, A. S.. Efeitos de sistemas de cultivo na densidade e macroporosidade do solo e no desenvolvimento radicular do milho em Latossolo Roxo. Pesquisa Agropecuária Brasileira, Viçosa, v.34, p.289-298, 1999.

DALMAGO, G. A.; BERGAMASCHI, H.; BERGONCI, J. I.; KRÜGER, C. A. M. B.; COMIRAN, F.; HECKLER, B. M. M.. Retenção e disponibilidade de água às plantas, em solo sob plantio direto e preparo convencional. Revista Brasileira Engenharia Agrícola Ambiental, v.13, n.7, p.855-864, 2009. DOI: http://dx.doi.org/10.1590/S1415-43662009000700007

DONAGEMA, G. K.; CAMPOS, D. V. B.; CALDERANO, S. B.; TEIXEIRA, W. G.; VIANA, J. H. M.. Manual de métodos de análise de solos. 2 ed. Rio de Janeiro: Embrapa Solos, 2011.

EMBRAPA. Empresa Brasileira de Pesquisa Agropecuária. Manual de métodos de análise de solos. 2 ed. Rio de Janeiro: Embrapa Solos, 1997.

FERNANDES, A. L. T.; PARTELLI, F. L.; BONOMO, R.; GOLYNSKI, A.. A moderna cafeicultura dos cerrados brasileiros. Pesquisa Agropecuária Tropical, v.42, n.2, p.231240, 2012. DOI: http://10.1590/S1983-40632012000200015

FONTANA, A.; TEIXEIRA, W. G.; BALIEIRO, F. C.; MOURA, T. P. A.; MENEZES, A. R.; SANTANA, C. I.. Características e atributos de Latossolos sob diferentes usos na região Oeste do Estado da Bahia. Pesquisa Agropecuária Brasileira, Brasília, v.51, n.9, p.1457-1465, 2016. DOI: http://dx.doi.org/10.1590/s0100-204×2016000900044.

GOZUBUYUK, Z.; SAHIN, U.; OZTURK, I.; CELIK, A.; ADIGUZEL, $M$. C.. Tillage effects on certain physical and hydraulic properties of a loamy soil under a crop rotation in a semiarid region with a cool climate. Catena, Turkey, v.118, p.195205, 2014. DOI:

https://doi.org/10.1016/j.catena.2014.01.006

HECKLER, J. C.; SALTON, J. C.. Palha: fundamento do Sistema Plantio Direto. Rio de Janeiro: Embrapa Agropecuária Oeste, 2002.

HICKMANN, C.; COSTA, L. M.; SCHAEFER , C. E. G. R.; FERNANDES, R. B. A.; ANDRADE, C. L. T.. Atributos físicohídricos e carbono orgânico de um Argissolo após 23 anos de diferentes manejos. Revista Caatinga, Mossoró, v.25, p.128-
136, 2012.

LAL, R.. Soil carbon sequestration to mitigate climate change. Geoderma, Columbus, v.123, p.1-22, 2004. DOI: https://doi.org/10.1016/j.geoderma.2004.01.032

LIPIEC, J.; HORN, R.; PIETRUSIEWICZ, J.; SICZEK, A.. Effects of soil compaction on root elongation and anatomy of different cereal plant species. Soil and Tillage Research, Poland, v.121, p.74-81, 2012. DOI: https://doi.org/10.1016/i.still.2012.01.013

LOSS, A.; BASSO, A.; OLIVEIRA, B. S.; KOUCHER, L. P.; OLIVEIRA, R. A.; KURTZ, C.; LOVATO, P. E.; CURMI, P.; BRUNETTO, G.; COMIN, J. J.. Carbono Orgânico Total e Agregação do Solo em Sistema de Plantio Direto Agroecológico e Convencional de Cebola. Revista Brasileira de Ciência do Solo, Viçosa, v.39, p.1212-1224, 2015. DOI: http://dx.doi.org/10.1590/01000683rbcs20140718.

MALHEIROS, R.. A influência da sazonalidade na dinâmica da vida no Bioma Cerrado. Revista Brasileira de Climatologia, v.19, p.113-128, 2016. DOI: http://dx.doi.org/10.5380/abclima.v19i0.48876

MAZURANA, M.; FINK, R. J.; SILVEIRA, H. V.; LEVIEN, R.; ZULPO, L.; BREZOLIN, D.. Propriedades físicas do solo e crescimento de raízes de milho em um Argissolos vermelho sob tráfego controlado de máquinas. Revista Brasileira de Ciência do Solo, Viçosa, v.36, n.5, p.1185-1195, 2013. DOI: http://dx.doi.org/10.1590/S0100-06832013000500008

MEURER, E. J.; CASTILHOS, D. D.; TEDESCO, M. J..

Fundamentos de química do solo. 2 ed. Genesis, 2004.

MORAES, M. T.; DEBIASI, H.; CARLESSO, R.; FRANCHINI, J. C; SILVA, V. R.. Limites críticos da resistência à penetração do solo em um Eutrudox. Revista Brasileira de Ciência do Solo, Viçosa, v.38, n.1, p.288-298, 2014. DOI: http://dx.doi.org/10.1590/S0100-06832014000100029

NEGREIROS NETO, J. V.; SANTOS, A. C.; GUARNIERI, A.; SOUZA, D. J. A. T.; DARONCH, D. J.; DOTTO, M. A.; ARAÚJO, A. S.. Variabilidade espacial de atributos físico-químicos de um Latossolo Vermelho-Amarelo distrófico em sistema plantio direto. Ciências Agrárias, Londrina, v.35, n.1, p.193204, 2014. DOI: http://10.5433/1679-0359.2014v35n1p193

NEVES JÚNIOR, F. A.; SILVA, P. A.; NORONHA, C. N.; CERRI, C. C.. Sistemas de manejo do solo na recuperação de uma pastagem degradada em Rondônia. Revista Brasileira de Ciência do Solo, Viçosa, v.37, n.1, p.232-241, 2013. DOI: http://dx.doi.org/10.1590/S0100-06832013000100024

NOGUEIRA, K. B.; ROQUE, C. G.; BORGES, M. C. R. Z.; TROLEIS, M. J. B.; BARRETO, R. F.; OLIVEIRA, M. P.. Atributos físicos do solo e matéria orgânica sob dois manejos e efeito residual da aplicação de calcário e gesso agrícola. Revista de la Facultad de Agronomía, La Plata, v.115, p.45-54, 2016.

NOSALEWICZ, A.; LIPIEC, J.. The effect of compacted soil layers on vertical root distribution and water uptake by wheat. Plant Soil, v.375, p.229-240. 2014. DOI: https://doi.org/10.1007/s11104-013-1961-0

NUNES, M. R.; DENARDIN, J. E.; FAGANELO, A.; PAULETTO, E. A.; PINTO, L. F. S.. Effect of seed drill with fixed shanks for 
deep action in soil under no-till. Brazilian Journal Soil Science, v.38, p.627-638, 2014.

NUNES, M. R.; DENARDIN, J. E.; PAULETTO, E. A.; FAGANELLO, A.; PINTO, L. F. S.. Mitigation of clayey soil compaction managed under no-tillage. Soil and Tillage Research, v.148, p.119-126, 2015. DOI: http://dx.doi.org/10.1016/j.still.2014.12.007

OLIVEIRA, F. P.; BUARQUE, D. C.; VIERO, A. C.; MERTEN, G. H.; CASSOL, E. A.; MINELLA, J. P. G.. Fatores relacionados à suscetibilidade da erosão em entressulcos sob condições de uso e manejo do solo. Revista Brasileira de Engenharia

Agrícola e Ambiental, Campina Grande, v.16, n.4, p.337-346, 2012. DOI: http://dx.doi.org/10.1590/S141543662012000400002

OLIVEIRA, P. R.; CENTURON, J. F.; ALMEIDA, C. X.; PELÁ, A.; PEREIRA, F. S.; CENTURION, M. A. P. C.. Physical properties of Oxisol under conventional corn cultivation and no-till management systems. Australian Journal of Crop Science, v.13, p.403-411, 2019. DOI:

http://10.21475/ajcs.19.13.03.p1323

PAREDES JUNIOR, F. P.; PORTILHO, I. I. R.; MERCANTE, F. M.. Atributos microbiológicos de um latossolo sob cultivo de cana-de-açúcar com e sem queima da palhada. Semana: Ciências Agrárias, Londrina, n.36, n.1, p.151-164, 2015. DOI: http://10.5433/1679-0359.2015v36n1p151

PRADO, R. M.; CENTURION, J. F.. Alterações na cor e no grau de floculação de um Latossolo Vermelho-Escuro sob cultivo contínuo de cana-de-açúcar. Pesquisa Agropecuária Brasileira, Brasília, v.36, n.1, p.197-203, 2001. DOI: http://dx.doi.org/10.1590/S0100-204X2001000100024

REICHERT, J. M.; SUZUKI, L. E. A. S.; REINERT, D. J.; HORN, R.; HAKANSSON, I.. Reference bulk density and critical degreeof-compactness for no-till crop production in subtropical highly weathered soils. Soil Tillage Research, v.102, p.242254, 2009. DOI: https://doi.org/10.1016/j.still.2008.07.002

REIS, D.A.; LIMA, C.L.R.; BAMBERG, A. L. Qualidade física e frações da matéria orgânica de um Planossolo sob sistema plantio direto. Pesquisa Agropecuária Brasileira, Brasília, v.51, n.9, p.1623-1632, 2016. DOI: http://dx.doi.org/10.1590/s0100-204×2016000900062

REIS, D. A.; LIMA, C. L. R.; BAMBERG, A. L.; RIBEIRO, P. L.. Compressibility and water availability in Albaqualf soils under different deployment times in no-tillage. Scientia Agricola, Piracicaba, v.75, p.361-443, 2018. DOI: http://dx.doi.org/10.1590/1678-992x-2016-0219

REIS, S. L. S.; VALE, R. M. C.; LOBÃO, J. S. B.. Identificação de áreas degradadas no oeste da Bahia através de técnicas de geoprocessamento. 2010.

REYNOLDS, W.D.; DRURY, C.F.; YANG, X.M.; FOX, C.A.; TAN C.S.; ZHANG, T.Q.. Land management effects on the nearsurface Physical quality of a clay loam soil. Soil and Tillage Research, v.96, p.316-330, 2007. DOI: http://10.1016/j.still.2007.07.003

RIBEIRO, J. F.; WALTER, B. M. T.. As principais fitofisionomias do Bioma Cerrado. In: SANO, S. M.; ALMEIDA, S. P.. Cerrado: ambiente e flora. Planaltina: EMBRAPA, 2008. p.89-166.
RIBEIRO, P. L.; BAMBERG, A. L.; REIS, D. A.; OLIVEIRA, A. C. B.. Condições físico-hídricas de Planossolo cultivado com soja em plantio direto e preparo convencional. Pesquisa Agropecuária Brasileira, Brasília, v51, n.9, p.1484-1491, 2016. DOI: http://dx.doi.org/10.1590/s0100204x2016000900047

ROLIM, J. I. M.; NICOLAU, F. E. A.; MOTA, A. M. D.; PINTO, A. A.; CAMARA, F. T.. Desenvolvimento e produtividade do milho em sistema plantio direto no cariri cearense. Revista Engenharia na Agricultura, Viçosa, v.27, n.2, p.122-131, 2019. DOI: https://doi.org/10.13083/reveng.v27i2.865

RÓS, A. B.; TAVARES FILHO, J.; BARBOSA, G. M. C.. Propriedades físicas de solo e crescimento de batata-doce em diferentes sistemas de preparo. Revista Brasileira de Ciência do Solo. Viçosa, v.37, n.1, p.242-250, 2012. DOI: http://dx.doi.org/10.1590/S0100-06832013000100025

ROSA, C. M.; CASTILHOS, R. M. V.; PAULETTO, E. A.; PILLON, C. N.; LEAL, O. A.. Conteúdo de carbono orgânico em Planossolo Háplico sob sistemas de manejo do arroz irrigado. Revista Brasileira de Ciência do Solo, v.35, p.1769$1776,2011$.

SALES, R. P.; PORTUGAL, A. F.; MOREIRA, J. A. A.; KONDO, M. K.; PEGORARO, R. F.. Qualidade física de um Latossolo sob plantio direto e preparo convencional no semiárido. Revista Ciência Agronômica, v.47, p.429-438, 2016.

SANO, E. E.; SANTOS, C. C. M.; SILVA, E. M.; CHAVES, J. M. Fronteira agrícola do oeste baiano: considerações sobre os aspectos temporais e ambientais. Geociências, São Paulo, v.30, p.479-489, 2011

SANO, E. E.; PINHATI, F. S. C.. Espaço rural do oeste baiano: identificação de áreas agrícolas sob sistema de plantio direto por meio de dados obtidos por câmera digital e satélite CBERS- 2 CCD. Geografia, São Paulo, v.34, p.117-129, 2009.

SILVA, A. L.; FARIA, M. A.; REIS, R. P.. Viabilidade do sistema de irrigação por gotejamento na cultura do cafeeiro (Coffea arabica L.). In: SIMPÓSIO BRASILEIRO DE PESQUISA DA CAFEICULTURA IRRIGADA, 6. Anais. Uberlândia: UFU, 2003. p.25-29.

SILVA, J. H.; SILVEIRA, P. M.; OLIVEIRA, J. P.. Alterações na densidade e na porosidade de um Latossolo cultivado com feijão causadas pelo sistema de preparo do solo. Campinas: IAC, 2008.

SILVA, R. F.; PORTILHO, I. I. R.; AQUINO, A. M.; OTSUBO, A A.; GALLO, A. S.; GUIMARÃES, M. F.. Análise conjunta de atributos físicos e biológicos do solo sob sistema plantio direto no Cerrado. Acta Iguazu, Cascavel, v.7, p.60-74, 2018.

SOANE, B. D.; BALL, B. C.; ARVIDSSON, J.; BASCH, G.; MORENO, F.; ROGER-ESTRADE, J.. No-till in northern, western and south-western Europe: A review of problems and opportunities for crop production and the environment. Soil and Tillage Research, v.118, p.66-87, 2012. DOI: https://doi.org/10.1016/j.still.2011.10.015

SAS. Statistical Analysis System Institute. Procedure guide for personal computers: version 9. Cary: SAS, 1999. 
STOLF, R.. Teoria e teste experimental de fórmulas de transformação dos dados de penetrômetro de impacto em resistência do solo. Revista Brasileira de Ciência do Solo, v.15, p.229-235, 1991.

TORRES, J. L. R.; FABIAN, A. J.; PEREIRA, M. G.. Alterações dos atributos físicos de um Latossolo Vermelho submetido a diferentes sistemas de manejo. Ciência e Agrotecnologia, v.35, n.3, p.437-445, 2011. DOI:

http://dx.doi.org/10.1590/S1413-70542011000300001

VOGEL, G. F.; MARTINKOSKI, L.; GRILLO, J. F.; MICHALOVICZ, L.; FEY, R.. Avaliação dos penetrômetros de impacto e eletrônico na determinação da resistência mecânica a penetração do solo. Revista Scientia Agraria, v.18, p.30-36, 2017.

A CBPC - Companhia Brasileira de Produção Científica (CNPJ: 11.221.422/0001-03) detém os direitos materiais desta publicação. Os direitos referem-se à publicação do trabalho em qualquer parte do mundo, incluindo os direitos às renovações, expansões e disseminações da contribuição, bem como outros direitos subsidiários. Todos os trabalhos publicados eletronicamente poderão posteriormente ser publicados em coletâneas impressas sob coordenação da Sustenere Publishing, da Companhia Brasileira de Produção Científica e seus parceiros autorizados. Os (as) autores (as) preservam os direitos autorais, mas não têm permissão para a publicação da contribuição em outro meio, impresso ou digital, em português ou em tradução. 